\title{
UMA ANÁLISE CRÍTICA DO CRESCIMENTO ECONÔMICO EM 2004
}

Marcelo Curado*

O crescimento de 5,2\% do Produto Interno Bruto (PIB) em 2004 constitui-se numa mudança importante no sinal do comportamento do produto, sobretudo quando comparado com o ano anterior. O resultado é importante e deve ser comemorado pelo governo federal, sobretudo porque foi obtido num contexto de cumprimento da meta de inflação e de um expressivo superávit nas contas externas.

Não obstante, algumas qualificações sobre este processo merecem ser realizadas. A primeira e mais evidente diz respeito à base comparação utilizada. O crescimento do PIB, em sua forma padrão, mensura a variação percentual do produto em termos reais de um ano em relação ao anterior. Como em 2003 o crescimento foi baixo, a base de comparação torna-se relativamente pequena, o que acentua o resultado obtido em 2004.

A análise torna-se mais precisa a partir da observação dos dados da tabela 01 abaixo.

Tabela 01. PIB real (Variação percentual em relação ao mesmo período do ano anterior)

\begin{tabular}{cccccccc}
\hline 2002 & 2003 & $2003 \mathrm{~T} 2$ & $2003 \mathrm{~T} 3$ & $2003 \mathrm{~T} 4$ & $2004 \mathrm{~T} 1$ & $2004 \mathrm{~T} 2$ & $2004 \mathrm{~T} 3$ \\
\hline 1,93 & 0,54 & 0,03 & $-0,19$ & 0,91 & 4,00 & 5,64 & 6,13 \\
\hline
\end{tabular}

Fonte: IPEADATA

O crescimento do PIB real de 6,13\% no terceiro trimestre de 2004 ocorre em relação a um terceiro trimestre de 2003 no qual a variação do produto foi negativa. O mesmo raciocínio é válido para o resultado do segundo trimestre de 2004. Neste mesmo período em 2003, a variação do PIB real foi praticamente nula.

Uma outra evidência dos limites deste processo de crescimento encontra-se nos seus impactos sobre o mercado de trabalho. Em geral, períodos de aquecimento relevante da economia acabam, com algum gap temporal, traduzindo-se numa ampliação dos rendimentos do fator trabalho.

Os dados apresentados na tabela 02 confirmam a hipótese de que o crescimento não é ainda significativamente forte para afetar o mercado de trabalho. O rendimento médio do trabalho é ainda inferior ao verificado no ano de 2002.

\footnotetext{
* Doutor em Economia pela Universidade de Campinas (UNICAMP). Professor do Departamento de Economia da Universidade Federal do Paraná (UFPR). Endereço eletrônico: mcurado@ufpr.br.
} 
Tabela 02. Rendimento médio real (em R\$)

\begin{tabular}{cccccccc}
\hline 2002 & 2003 & $2004 \mathrm{~T} 1$ & $2004 \mathrm{~T} 2$ & $2004 \mathrm{~T} 3$ & $2004 \mathrm{M} 09$ & 2004 M10 & 2004 M11 \\
\hline $1.028,76$ & 940,64 & 919,02 & 924,39 & 925,74 & 922,40 & 925,35 & 964,80 \\
\hline Fonte: IPEADATA
\end{tabular}

Além desta qualificação, deve ser incorporada ao debate uma análise do cenário internacional em 2004. O resultado obtido pela economia brasileira precisa ser comparado ao do resto do mundo. Tratar o crescimento econômico de um país isoladamente, tende a desprezar o papel fundamental do cenário econômico internacional, o qual em diversas situações pode jogar um papel chave na definição da aceleração ou da retração do produto, sobretudo em economias com elevado grau de abertura comercial e da conta de capital.

Por fim, é relevante também estabelecer uma discussão sobre o comportamento dos componentes da demanda agregada no crescimento e seus vínculos com a condução da política econômica recente. Vejamos, inicialmente, a questão da economia internacional.

De acordo com o FMI, a economia mundial cresceu em 2004 aproximadamente 5\%. O crescimento da economia brasileira em 2004 situou-se, portanto, em torno da média internacional. A separação entre economias desenvolvidas e em desenvolvimento revela também algumas informações pertinentes. Em 2004, os países desenvolvidos cresceram em torno de 3,6\%, taxa bastante elevada para os padrões destas economias. Já as economias em desenvolvimentos cresceram 6,6\% em 2004. A taxa de crescimento para o México, a Colômbia e a Bolívia, por exemplo, foram todas próximas à da economia brasileira. Chile, Argentina e, sobretudo Venezuela, cresceram a taxas significativamente superiores (5,5\%, $7,0 \%$ e $12,0 \%$, respectivamente).

Os dados selecionados permitem concluir que o crescimento para a economia brasileira em 2004 deve ser considerado "normal" do ponto de vista comparativo. Além de qualificar melhor o resultado de 2004, estes dados também permitem evidenciar um ponto de grande importância no debate recente sobre a política econômica, qual seja que em grande medida o crescimento de 2004 deve ser atribuído à conjuntura econômica internacional favorável.

Crescimento da economia mundial significa crescimento da demanda por produtos no mercado internacional, o que pode ser comprovado pela elevação no quantum exportado global. O volume de exportações dos países desenvolvidos cresceu 7,8\%, enquanto os países em desenvolvimento registraram um crescimento de 11\% neste volume. Neste contexto, verifica-se também a elevação dos preços em dólar dos produtos transacionados. O preço dos 
produtos manufaturados cresceu em torno de 7,5\%. O petróleo e seus derivados em torno de $28,9 \%$ e os produtos primários excluindo petróleo registraram um acréscimo de 16,8\% em seus preços. O cenário foi, portanto, francamente favorável aos países exportadores de petróleo e derivados e de produtos primários. Todos os grupos de países em desenvolvimento apresentaram uma melhora em seus termos de troca, o que não se verificou para os países desenvolvidos, sobretudo para a União Européia.

Estas informações reforçam o argumento de que o cenário em 2004 foi muito favorável, sobretudo para os países em desenvolvimento exportadores de petróleo. No caso brasileiro, esta forte expansão da demanda internacional por produtos e serviços concomitante a melhoria nos termos de troca, permitiu a elevação das exportações e do saldo comercial, como pode ser observado nas tabelas 3 e 4 .

Tabela 03. Exportações (FOB) - (em milhões de dólares)

\begin{tabular}{rrrrrrrr}
\hline 2003 & 2004 & $2004 \mathrm{~T} 2$ & $2004 \mathrm{~T} 3$ & $2004 \mathrm{~T} 4$ & $2004 \mathrm{M} 11$ & $2004 \mathrm{M} 12$ & $2005 \mathrm{M} 01$ \\
\hline 73.084 & 96.475 & 23.858 & 26.972 & 26.197 & 8.159 & 9.194 & 7.444 \\
\hline
\end{tabular}

Fonte: IPEADATA

Tabela 04. Balança comercial (FOB) - (em milhões de dólares)

\begin{tabular}{|c|c|c|c|c|c|c|c|}
\hline 2003 & 2004 & $2004 \mathrm{~T} 2$ & $2004 \mathrm{~T} 3$ & $2004 \mathrm{~T} 4$ & 2004 M11 & 2004 M12 & 2005 M01 \\
\hline 24.794 & 33.693 & 8.877 & 10.085 & 8.594 & 2.078 & 3.511 & 2.183 \\
\hline
\end{tabular}

onte: IPEADATA

Embora uma medida mais precisa do impacto das exportações sobre o produto mereça uma análise mais técnica, preferencialmente uma análise econométrica, parecem existir poucas dúvidas de que o bom resultado de 2004 encontra fortes vínculos com a expansão das vendas no mercado internacional, sobretudo no primeiro semestre do ano, quando o mercado interno dava sinais de desaquecimento.

Estes resultados foram frutos, no entanto, de um contexto internacional específico (forte crescimento da demanda mundial com melhoria nos termos de troca para os países em desenvolvimento) com a manutenção de uma taxa de câmbio real durante o ano de 2003 e o primeiro trimestre de 2004 francamente favorável às exportações.

Os movimentos internacionais de desvalorização do dólar e alguns sinais de desaquecimento na demanda por bens primários devem ser vistos com cuidado pela equipe econômica, o que aparentemente não tem ocorrido.

Declarações do Secretário de Política Monetária do Banco Central, Marcos Lisboa, confirmam a visão da instituição de que o Real valorizado não tem produzido efeitos de 
redução do superávit comercial. Vale lembrar, no entanto, que os contratos de exportações são firmados com um lag temporal não desprezível. Em outras palavras, o efeito da valorização do Real deverá ser sentido apenas a partir do segundo semestre deste ano, quando os contratos passarem a incorporar as taxas de câmbio vigentes.

Por outro lado, os dados disponíveis demonstram que a partir do segundo semestre de 2004, os efeitos positivos das vendas para o resto do mundo começaram a contaminar o mercado interno. Os investimentos, tanto como proporção do PIB em termos nominais, quanto em termos de variação em termos reais apresentaram forte retomadas, em especial a partir do terceiro trimestre daquele ano, como pode ser observado a partir dos dados das tabelas 5 e 6.

Tabela 05. Taxa de investimento nominal (em percentagem do PIB)

\begin{tabular}{cccccccc}
\hline 2002 & 2003 & $2003 \mathrm{~T} 2$ & $2003 \mathrm{~T} 3$ & $2003 \mathrm{~T} 4$ & $2004 \mathrm{~T} 1$ & $2004 \mathrm{~T} 2$ & $2004 \mathrm{~T} 3$ \\
\hline 18,32 & 17,78 & 16,95 & 17,84 & 17,92 & 19,10 & 18,88 & 21,01 \\
\hline
\end{tabular}

Fonte: IPEADATA

Tabela 06. Investimento real (Variação percentual em relação ao mesmo período do ano anterior)

\begin{tabular}{cccccccc}
\hline 2002 & 2003 & $2003 \mathrm{~T} 2$ & $2003 \mathrm{~T} 3$ & $2003 \mathrm{~T} 4$ & $2004 \mathrm{~T} 1$ & $2004 \mathrm{~T} 2$ & $2004 \mathrm{~T} 3$ \\
\hline$-4,16$ & $-5,13$ & $-8,96$ & $-7,63$ & $-3,57$ & 1,84 & 13,41 & 20,13 \\
\hline
\end{tabular}

Fonte: IPEADATA

A preocupação neste caso encontra-se na política monetária. O Banco Central tem sistematicamente elevado o patamar da taxa de juro Selic nos últimos meses. A literatura internacional que estuda os mecanismos de transmissão da política monetária demonstra que alterações na taxa de juros afetam a demanda agregada, via alteração nas decisões de gastos com consumo e investimento, num período que varia entre 6 e 9 meses.

No caso brasileiro, estudos do próprio Banco Central demonstram que o gap temporal entre a variação da taxa e seus efeitos sobre a demanda agregada é de 6 meses. Desta forma, e desde que estes estudos econométricos estejam corretos, os efeitos das atuais elevações da taxa básica deveriam ser sentidos apenas no primeiro trimestre de 2005. O argumento de que a taxa de juros não está alta porque a economia está crescendo ignora as considerações sobre o gap temporais acima expostas, minimizando, de forma equivocada, as recentes decisões do Copom.

Por fim, o crescimento do consumo em 2004 apresenta como característica marcante o fato de estar concentrado na expansão dos setores de bens de consumo duráveis, com destaque para a indústria automobilística e os produtos eletroeletrônicos. Dados do IBGE, 
ainda preliminares, apontam para uma expansão destes setores da ordem de $20 \%$ em relação ao ano anterior. Boa parte deste crescimento pode ser explicada por políticas de concessão de crédito que passam à margem da atual política monetária, tais como as políticas de financiamento de automóveis e pela retomada do endividamento das famílias. Uma evidência de que a expansão de 2004 ainda não afetou de forma significativa a renda dos trabalhadores é que o setor de bens de consumo não duráveis apresentou em 2004 um crescimento reduzido (em torno de $5 \%$ ).

De forma sintética, apresentam-se para reflexão as seguintes considerações sobre o crescimento econômico em 2004:

1. A taxa de crescimento da economia brasileira manteve-se próxima à média da economia mundial e abaixo da verificada para o conjunto dos países em desenvolvimento;

2. O crescimento do produto encontra fortes vínculos com a expansão das exportações, sobretudo no primeiro semestre do ano. Esta expansão, no entanto, é fruto de uma combinação de elementos altamente favoráveis para a expansão das vendas no mercado internacional, com destaque para: a) forte crescimento da economia mundial, sobretudo da demanda por matérias-primas; b) melhoria nos termos de troca para as economias em desenvolvimento e c) fechamento de contratos com Real desvalorizado em termos reais contra os principais parceiros de países desenvolvidos;

3. A retomada dos investimentos e do consumo pode ser contida pela atual política monetária de elevação da taxa de juros;

4. Forte concentração da expansão nos setores de bens de consumo duráveis e resultados diminutos na expansão dos setores de bens de consumo não duráveis sugerem que o crescimento do consumo se deu a partir de forte endividamento das famílias e que a retomada do crescimento ainda não atingiu de forma substantiva a remuneração dos trabalhadores. 
